\section{Meio Ambiente, Transportes e Poluição}

Olívio Patrício, Universidade Técnica de Lisboa

\section{Environment, Transport and Pollution}

\section{Resumo:}

Este texto trata alguns aspectos relacionados com o ruído e a poluição atmosférica os quais constituem dois dos principais problemas ambientais que contribuem para a degradação da qualidade de vida de grande parte da população no mundo e afectam o Homem nos planos físico, psíquico e social. Este problema assume uma dimensão particular nos meios urbanos, onde vive a maior parte da população portuguesa e europeia. Esta problemática é ainda reforçada pelo aumento incessante do número de veículos accionados por motores de combustão interna, consumindo combustíveis fósseis.

Os transportes terrestres têm contribuído em grande parte para a degradação da qualidade de vida nos centros urbanos, onde a poluição atmosférica e a poluição sonora afectam praticamente toda a população. $\mathrm{O}$ aumento dos problemas ambientais ligados à poluição do ar, da água, dos solos, ao ruído, à produção de resíduos e à utilização da energia reflectem sobretudo, o comportamento e a interacção do Homem com o ambiente. A Educação ambiental deverá promover simultaneamente a construção do conhecimento nesta área, o desenvolvimento de comportamentos e atitudes necessários à utilização racional dos transportes e de todas as infra-estruturas, de modo a diminuir os efeitos nefastos para o ambiente e a consciencialização sobre os efeitos prejudiciais do ruído e da poluição atmosférica para o Homem e em nível ambiental.

Palavras Chave: Meio Ambiente; Poluição Atmosférica; Ruído.
Abstract:

This text is about some aspects concerning the noise and the atmospheric pollution which constitute two of the main environmental problems that contribute for the degradation of quality of life of great part of the world's population. They affect the Man considering his physical, psychic and social orders. This problem assumes a particular dimension in the urban areas, where most of the Portuguese and European populations live. This trouble has been strengthening by the increase in the number of vehicles with internal combustion engines using fossil fuel.The terrestrial transport has contributed to a large extent of the degradation of the quality of life in the urban centers, in which the atmospheric pollution and the sonorous pollution practically affect all the population. The increase of environmental problems Concerning to the air pollution, the water, the soils, the noise, the production of residues and the use of the energy reflect the Man's behavior and his interaction with the environment. The Environmental Education will need to promote the construction of the knowledge in this area, the development of behaviors and necessary attitudes related to the rational use of the transports, and the infrastructure systems as a whole, in order to diminish the ominous effects on the environment as well as to raise awareness on the harmful effects of the noise and the atmospheric pollution on man and the environment.

Keywords: Environment; Atmospheric Pollution; Noise. 


\section{Introdução}

"A protecção e valorização ambientais não são fins em si mesmos, antes servem valores essenciais como a dignidade e a integridade do homem e da sua relação com a natureza".

MARN (1995) Plano Nacional da Política de Ambiente

A poluição acústica, assim como, a poluição das águas e a poluição atmosférica constituem os maiores problemas ambientais com que a sociedade moderna se confronta. O aumento da poluição atmosférica é responsável por efeitos nefastos na saúde de todos os seres vivos, em particular do homem, nas florestas, na diminuição da produção agrícola e provoca grandes desequilíbrios nos ecossistemas.

Os transportes constituem, provavelmente, um dos meIhores exemplos da relação entre o paradigma social, a tecnologia, a economia e o ambiente.

Os transportes interagem com o ambiente e a sociedade a vários níveis. Interagem em nível da mobilidade, da saúde e da segurança. No âmbito da economia interagem com o emprego, o comércio, o turismo e a competividade e em nível do ambiente originam poluição atmosférica, ruído, influenciando as mudanças climáticas e a poluição das águas.

O aumento incessante dos níveis sonoros, especialmente nos meios urbanos, suburbanos e nas proximidades dos grandes eixos rodoviários, com todas as consequências negativas para o bem-estar físico e psíquico dos indivíduos, tem levado as diferentes entidades públicas e privadas a tentar solucionar este grave problema ambiental. As novas Directivas e Normas Europeias que têm sido publicadas sobre o ruído ambiental, isolamento acústico em edifícios, ruído na indústria, ruído emitido por equipamentos e veículos, têm sido igualmente transpostas para a legislação portuguesa.

As questões ambientais têm sido uma preocupação presente em Portugal a diferentes níveis desde há algum tempo.

Em Portugal, as primeiras referências em relação a questões ambientais encontram-se no III Plano de Fomento (1968 a 1973).
A Constituição Portuguesa de 1976, no seu Artigo 66, estabelece os "direitos do ambiente":

1. Todos têm direito a um ambiente de vida humano, sadio e ecologicamente equilibrado e o dever de o defender.

2. Para assegurar o direito ao ambiente, no quadro de um desenvolvimento sustentável, incumbe ao Estado, por meio de organismos próprios e com o envolvimento e a participação dos cidadãos: Prevenir e controlar a poluição e os seus efeitos e as formas prejudiciais de erosão; Ordenar e promover o ordenamento do território, tendo em vista uma correcta localização das actividades, um equilibrado desenvolvimento sócio-económico e a valorização da paisagem; Criar e desenvolver reservas e parques naturais e de recreio, bem como classificar e proteger paisagens e sítios, de modo a garantir a conservação da natureza e a preservação de valores culturais de interesse histórico ou artístico; Promover o aproveitamento racional dos recursos naturais, salvaguardando a sua capacidade de renovação e a estabilidade ecológica, com respeito pelo princípio da solidariedade entre gerações; Promover, em colaboração com as autarquias locais, a qualidade ambiental das povoações e da vida urbana, designadamente no plano arquitectónico e da protecção das zonas históricas; Promover a integração de objectivos ambientais nas várias políticas de âmbito sectorial; Promover a educação ambiental e o respeito pelos valores do ambiente; Assegurar que a política fiscal compatibilize desenvolvimento com protecção do ambiente e qualidade de vida."

Constata-se que desde 1977 se inicia no domínio ambiental uma participação activa nas reuniões organizadas em nível internacional, em seminários organizados pelo Conselho da Europa e na Conferência Internacional de Educação Ambiental que teve lugar na Geórgia, promovida pela UNESCO e pelo Programa das Nações Unidas para o Ambiente. Desta Conferência resultou a Declaração de Tbilissi, no qual são assinalados os conceitos e princípios de Educação Ambiental, que a partir daí têm 
orientado as acções empreendidas aos diferentes níveis.

Em 1986 a entrada de Portugal na Comunidade Económica Europeia (CEE), constituiu outra etapa decisiva para dar mais visibilidade e consistência à política ambiental no nosso país. Foi igualmente desenvolvido o processo de institucionalização da Política Pública de Ambiente, conduzindo, nomeadamente, à publicação, em 1987, de dois diplomas legais fundamentais: a Lei de Bases do Ambiente (Lei 11/87 de 7 de Abril) e a Lei das Associações de Defesa do Ambiente (Lei n¹0/87 de 4 de Abril) e ao início do processo de transição e integração de directivas comunitárias em diferentes áreas.

No quadro da Lei de Bases do Ambiente foi criado o Instituto Nacional do Ambiente (INamb) com competências no domínio da formação e informação dos cidadãos, através do "estudo e promoção de projectos especiais de educação ambiental, de defesa do ambiente e do património construído", o qual veio promover significativamente as práticas de Educação Ambiental em Portugal.

A publicação da Lei de Bases do Sistema Educativo, em 1986, vem reconhecer a Educação Ambiental nos novos objectivos de formação dos estudantes em todos os níveis de ensino.

A Comunidade Europeia em Maio de 1988 sobre a educação em matéria de ambiente, sublinhava a necessidade de iniciativas que melhorassem a cooperação entre os sistemas educativos com o objectivo de facilitar a transferência e a comparação das iniciativas de Educação Ambiental tomadas pelos diferentes Estados Membros.

A Educação Ambiental é considerada um instrumento importante no processo de mudança de valores, atitudes e comportamentos que visam a diminuição dos problemas ambientais, reconhecidos como uma ameaça para o planeta e simultaneamente para o bem-estar e para a qualidade de vida.

O problema das relações entre o homem e o ambiente não nasceu agora, é de sempre, mas assumiu uma dimensão nova que envolve riscos que poderão ser fatais se não se integrar com rapidez nos objectivos prioritários da for- mação do homem. A Educação Ambiental (...) é um modelo integrador de toda a aquisição de conhecimentos advindos dos ensinos formal e não formal e da própria vida, como força geradora de um novo humanismo capaz de conciliar três componentes até agora sempre desencontradas: o desenvolvimento, a que todos os povos aspiram com direito, a identidade cultural, matriz da sociedade,e o ambiente que a enquadra. (EVANGELISTA, p. 117-118, 1992).

A Educação Ambiental deve promover simultaneamente, a construção do conhecimento, o desenvolvimento de atitudes necessárias à preservação e melhoria da qualidade ambiental e a cidadania activa.

A médio e longo prazos, a chave central desse
futuro sustentável da política de ambiente pas-
sa, sem nenhuma dúvida, pelo entendimento
da Educação Ambiental como elemento decisi-
vo da competência cívica do nosso tempo: nos
dias que correm não se pode ser cidadão sem
algumas competências ambientais mínimas.
Trata-se de uma outra e nova forma de alfabeti-
zação. Essas competências que hoje se afirmam
e desenvolvem nas escolas, no trabalho muitas
vezes silencioso e invisível de animadores cul-
turais, de professores, de organizações não go-
vernamentais, são tão fundamentais como o fo-
ram e sempre serão o ler, o escrever e o contar.
(SOROMENHO-MARQUES, p. 104, 1998).

Os objectivos deste texto situam-se no âmbito da promoção do conhecimento e da sensibilização dos diversos actores sociais sobre questões ambientais, em particular, sobre as implicações para o ambiente e para o homem da poluição sonora e atmosférica originada pelos transportes na sociedade contemporânea.

\section{Transportes, Poluição Atmosférica e Ruído}

De acordo o Decreto-Lei n²76/99, de 23 de Julho, Poluente Atmosférico são "substâncias introduzidas, directa ou indirectamente, pelo homem no ar ambiente, que exercem uma acção nociva sobre a saúde humana e ou meio ambiente". 
Apesar dos esforços feitos pelos construtores de veículos accionados por motores de combustão interna, no sentido de respeitarem os níveis de emissões impostos pelas normas europeias, cada vez mais limitantes, e como o número desses veículos em circulação tem vindo a aumentar, esta situação faz dos transportes o principal responsável pelas emissões dos diferentes poluentes atmosféricos.

Dados da comunidade Europeia indicam que os transportes são responsáveis por cerca de um quarto das emissões de CO2 da UE e contribuem de forma significa- tiva para a perda de qualidade do ar (partículas, NOx, HC e $(\mathrm{CO})$ e problemas de saúde associados, em especial nas zonas urbanas (COMISSÃO EUROPEIA, 2010).

A Partir de 1992 (Euro l) os níveis de emissões de poluentes limitados por legislação têm vindo a diminuir, havendo actualmente legislação diferente para veículos com motores a gasolina e a Diesel, voltou-se a introduzir limites para os $\mathrm{HC}$ e NOx e introduziu-se limitação na produção de $\mathrm{CO}_{2}$ (Quadro 1).

\begin{tabular}{|c|c|c|c|c|c|c|c|c|c|}
\hline & Directiva & data & Tipo & $\begin{array}{l}\mathrm{CO}(\mathrm{g} / \\
\mathrm{km})\end{array}$ & $\begin{array}{l}\mathrm{HC}(\mathrm{g} / \\
\mathrm{km})\end{array}$ & $\begin{array}{l}\text { NOx }(g / \\
k m)\end{array}$ & $\begin{array}{l}\mathrm{HC}+\mathrm{NO} \times(\mathrm{g} / \\
\mathrm{km})\end{array}$ & $\begin{array}{l}\text { part. } \\
(\mathrm{g} / \mathrm{km})\end{array}$ & $\begin{array}{l}\mathrm{CO} 2 \\
(\mathrm{~g} / \mathrm{km})\end{array}$ \\
\hline Euro I & $91 / 441 /$ CEE & 1992 & & 2.72 & & & 0.97 & 0.19 & \\
\hline \multirow{2}{*}{ Euro II } & \multirow[t]{2}{*}{$94 / 12 / C E$} & \multirow[t]{2}{*}{1997} & gasolina & 2.2 & & & 0.5 & & \\
\hline & & & Diesel & 1.0 & & & 0.7 & 0.08 & \\
\hline \multirow{2}{*}{ Eurolll } & \multirow[t]{2}{*}{$98 / 69 / C E$} & \multirow[t]{2}{*}{2000} & gasolina & 2.3 & 0.2 & 0.15 & - & - & \\
\hline & & & Diesel & 0.64 & - & 0.5 & 0.56 & 0.05 & \\
\hline \multirow{2}{*}{ Eurolv } & \multirow[t]{2}{*}{$98 / 69 / \mathrm{CE}$} & \multirow[t]{2}{*}{2005} & gasolina & 1.0 & 0.1 & 0.08 & - & - & \\
\hline & & & Diesel & 0.5 & - & 0.25 & 0.3 & 0.025 & \\
\hline \multirow{2}{*}{ Eurov } & & \multirow[t]{2}{*}{2008} & gasolina & 1.0 & 0.075 & 0.06 & - & 0.005 & \\
\hline & & & Diesel & 0.5 & - & 0.20 & 0.25 & 0.005 & 140 \\
\hline
\end{tabular}

Quadro 1 - Limites dos níveis de emissões de poluentes para automóveis na União Europeia. Fonte: (Martins, 2011) 
Verifica-se que nos últimos 20 anos, houve uma redução importante dos teores das emissões regulamentadas pelas normas, particularmrnte em nível das partículas que passaram de 0,19 g/km na Norma Euro I em 1992, para 0,005 g/km na Norma Euro V em 2008.

O Regulamento da União Europeia, n. ${ }^{\circ}$ 459/2011 da Comissão, de 12 de Maio, chama a atenção para o perigo das partículas: Estas partículas emitidas pelos veículos podem depositar-se nos alvéolos dos pulmões humanos, causando eventualmente doenças respiratórias e cardiovasculares e uma crescente mortalidade. É, pois, do interesse público, assegurar um nível elevado de proteção contra essas partículas. A Figura 1 representa a evolução dos níveis de emissão de poluentes na União Europeia, para veículos pesados e semi-pesados, limitados pela aplicação das várias Directívas até aos nossos dias.

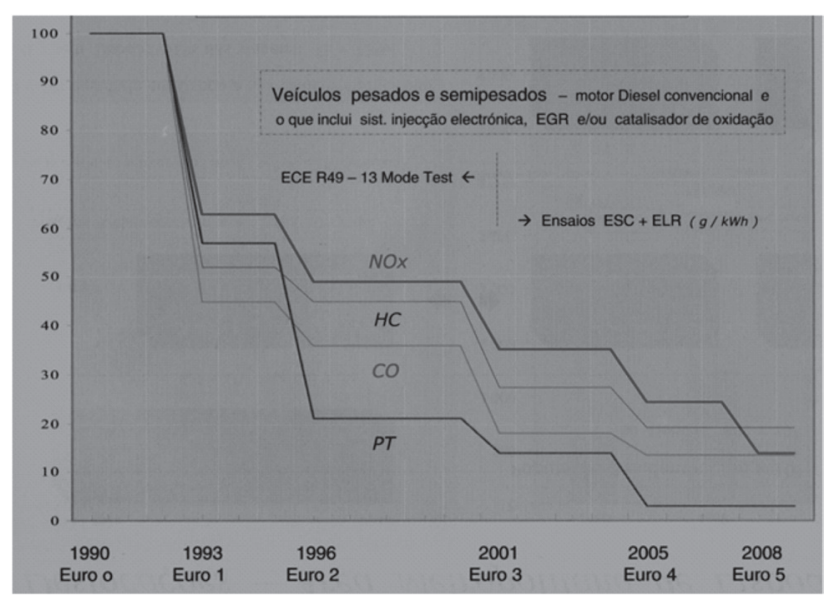

Figura 1: Evolução dos níveis de emissão de poluentes na União Europeia (Nabais, 2005)

As partículas são produzidas em grande parte pelos motores Diesel. Estas partículas, extremamente pequenas após saírem dos escapes dos veículos, podem permanecer em suspensão no ar durante várias horas. São muito nocivas para a saúde e consideradas cancerígenas. Ao serem aspiradas pelo aparelho respiratório humano, permanecem nos alvéolos dos pulmões muito tempo após a sua inalação e têm efeitos respiratórios e cardiovasculares bem identificados: bronquepatias, alergias e doenças cardíacos. De acordo com a OMS a poluição ligada aos transportes mata cada ano 500000 pessoas no mundo.
Em 2004, um estudo do IIASA (Internacional Institute for Applied Systems Analysis) mostra que as partículas poluentes emitidas pela carburação reduziam de dois a oito anos a esperança de vida dos Europeus.

Quanto ao ruído e às consequências da poluição acústica sobre o Homem, a maior parte dos especialistas são unânimes em considerar que a exposição a ruídos intensos pode causar graves problemas à saúde, provocar sinais patológicos, como a diminuição da capacidade de concentração, dificultar a comunicação e a aprendizagem, originar irritabilidade, fadiga, dores de cabeça, aumento da frequência cardíaca e da pressão arterial, provocar interferências no metabolismo do organismo com riscos de distúrbios cardiovasculares, podendo ainda, tornar a perda auditiva irreversível.

O ruído ambiente, causado pelo tráfego, pelas actividades industriais e de recreio e o ruído de vizinhança, constituem um dos principais problemas ambientais e são fonte de um número crescente de reclamações por parte da população.

O ruído é, também, responsável por numerosos efeitos psico-sociais, principalmente degradação da qualidade de vida, modificação das atitudes e do comportamento social, nomeadamente agressividade e perturbações do comportamento, conflitos interrelacionais e familiares e diminuição do respeito em relação ao outro.

O ruído vem reforçar as desigualdades sociais, na medida em que incide, sobretudo, nas classes sociais mais desfavorecidas que não têm meios de se protegerem do mesmo, seja em nivel habitacional, como seja em nivel do trabalho.

Nas diferentes partes do mundo, cada lugar é caracterizado por um conjunto de sons/ruídos. A percepção que cada um tem acerca dos sons/ ruídos pode apresentar significados diferentes de acordo com o meio cultural, habitacional, profissional ou recreativo em que se encontra. Esta percepção depende, do nível e duração do ruído, da composição do espectro sonoro, da sensibilidade auditiva, estado de espírito, história e cultura de cada um. Contudo, diversos aparelhos de medida, nomeadamente os sonómetros e os dosímetros, permitem quantificar as componentes objectivas do ruído. 
O ruído tem sido tema de inúmeras investigações que visam compreender os seus modos de acção e os seus mecanismos de funcionamento e interacção. Apesar disso, o ruído continua a ser um dos domínios menos conhecidos, tanto no que diz respeito aos seus efeitos sobre o homem, como sobre as suas repercussões económicas e sociais. Este desconhecimento deve-se, em primeiro lugar, à dificuldade em avaliar as consequências reais a curto, médio ou longo prazo, devido aos seres humanos serem susceptíveis de se adaptarem ao ruído e, por conseguinte, esta adaptação vem "mascarar" a totalidade ou parte destes efeitos a vários níveis: no plano físico (lesões nos órgãos auditivos, perturbações da circulação, perturbações do sono); no plano psicológico (irritação, stress e incomodidade); no plano social (perturbação da comunicação, diminuição do rendimento no trabalho).

Esta dificuldade é reforçada pelo facto de o ruído comportar um grande número de componentes subjectivas, podendo ser percebido de maneiras muito diferentes por duas pessoas, com reacções variáveis, as quais podem dar lugar a interpretações geralmente contraditórias ou ambíguas.

\section{Funcionamento do Sistema Auditivo}

Para a existência de som/ruído é necessário que haja uma fonte sonora (emissão), um meio de transmissão e um receptor (Figura 2).

O som/ruído tem por origem as vibrações mecânicas que se produzem num meio elástico, sólido, líquido ou gasoso (por exemplo cordas vocais, colunas de som, órgãos de máquinas, etc.). Estas vibrações propagam-se no meio ambiente que geralmente é o ar, e atingem os nossos ouvidos, no qual são captadas pelo ouvido externo e encaminhadas pelo canal auditivo para a membrana do tímpano que entra em vibração.
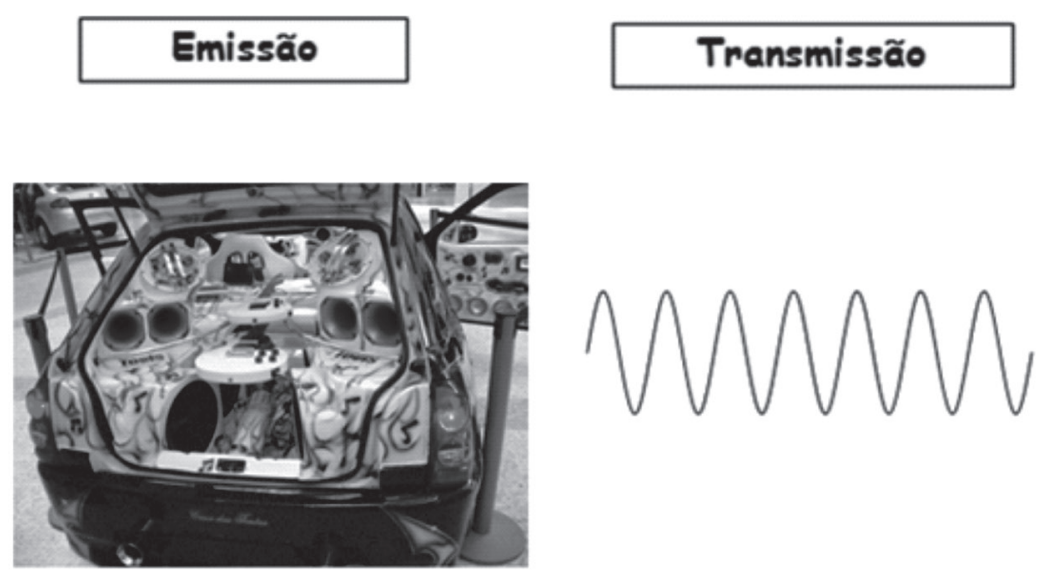

\section{Transmissão}

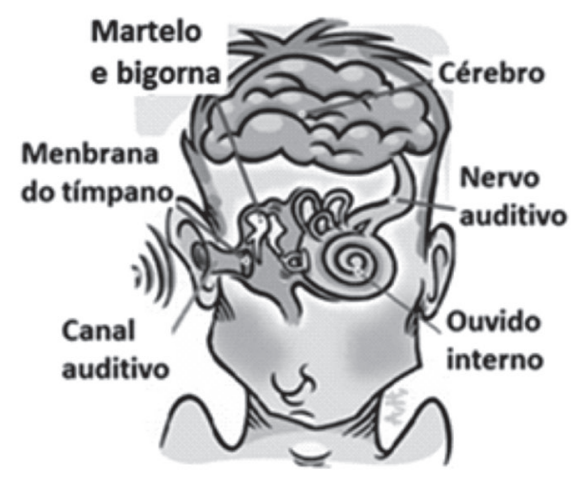

Figura 2: Funcionamento do sistema auditivo 
Esta vibração é amplificada ou atenuada no ouvido médio pelos ossículos (martelo, bigorna e estribo) e transmitida ao ouvido interno que transforma essa vibração mecânica em sinais eléctricos, que são transmitidos pelo nervo óptico ao cérebro, que tem a função de os interpretar. Se as informações recebidas pelo cérebro forem desagradáveis, se produzirem incómodo e se não tiverem qualquer significado, então, são identificadas como sendo ruído. Se as informações recebidas pelo cérebro forem agradáveis ou se transmitirem uma menagem, então são identificadas como sendo um som. Porém o que é som para nós, pode ser ao mesmo tempo ruído para os nossos vizinhos. É este tipo de conflitos que o Estado tem de gerir através do Regulamento Geral do Ruído e para a qual a população deve estar sensibilizada, através de medidas apropriadas.

O sistema auditivo humano de jovens com audição normal, é sensíveil a sons cuja frequência está compreendida sensivelmente entre $20 \mathrm{~Hz}$ e os $20000 \mathrm{~Hz}$. Abaixo dos $20 \mathrm{~Hz}$ temos os infrasons, acima de $20000 \mathrm{~Hz}$ temos os ultra-sons. Em relação à exposição prolongada a infra-sons e a ultra-sons, apesar de estarem fora da nossa zona de audição, não se exclui a possibilidade de serem nefastos para a saúde humana, principalmente se o nível sonoro e o tempo de exposição for muito elevado. A zona de audição dos jovens está compreendida entre o limiar de audibilidade, que varia segundo a frequência de 0 a $40 \mathrm{~dB}$, e o limiar de dor, que se situa por volta de $120 \mathrm{~dB}$.

A sensibilidade do ouvido humano varia com a frequência do ruído. O ouvido humano é menos sensível aos sons graves e agudos. Para ter em conta esta característica do ouvido os níveis sonoros devem ser corrigidos com as ponderações dadas na Figura 3.

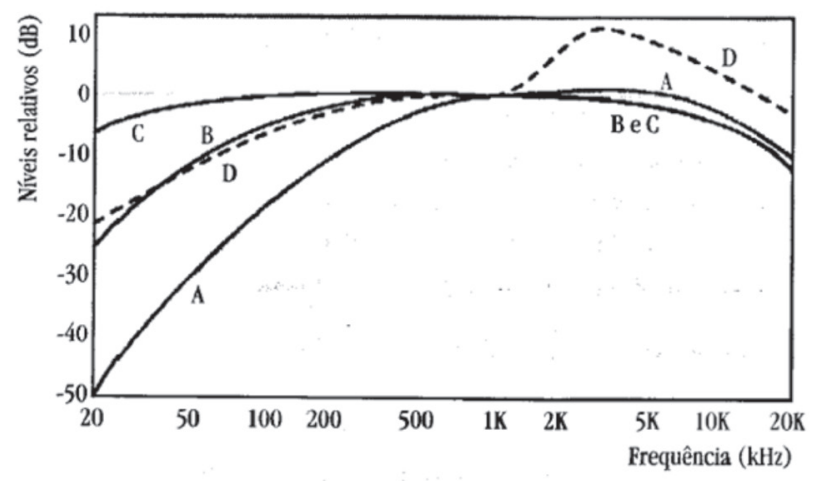

Figura 3: Malhas de ponderação: A, B, C, D (Fonte: Patrício, 2010)
O sonómetro está equipado com filtros de ponderação e o mais correntemente utilizado de acordo com a nossa legislação é o filtro A, que corrige o nível sonoro recebido como está indicado na figura, dando assim a pressão sonora percebida pelo ouvido humano, tendo em conta as variações da sua sensibilidade em função da frequência.

O nível de pressão acústica medida em dB e ponderado com o filtro "A" exprime-se em dB(A).

A propagação do ruído ao ar livre é influenciada por diversos factores que contribuem para a sua atenuação. Em qualquer ponto, do campo acústico, o nível de pressão sonora num receptor é consequência directa do nível de potência sonora da fonte emissora e da atenuação total verificada ao longo de todo o percurso da onda sonora entre o emissor e receptor. Esta atenuação é influenciada pelos seguintes factores: atenuação por divergência geométrica; atenuação devido ao ar; atenuação devido à absorção pelo solo; acção dos gradientes de temperatura e velocidade do vento; atenuação devida a densa vegetação; atenuação devido a propagação em zona industrial; atenuação devida à proximidade de paredes (edifícios); acção do nevoeiro e da chuva.

Os níveis sonoros elevados provocam uma alteração do sistema auditivo, pouco adaptado a suportá-los durante longos períodos. Trata-se principalmente, da degradação de uma parte das células ciliadas da orelha interna, células frágeis, pouco numerosas e que não se renovam, o que provoca uma perda definitiva da audição.

É considerado que perturbações auditivas podem ser observadas após uma exposição a um nível de $85 \mathrm{~dB}(\mathrm{~A})$ (por exemplo, rua com muito trânsito) e, sobretudo uma exposição a um nível próximo de $100 \mathrm{~dB}(\mathrm{~A})$ (por exemplo, discotecas, concertos). Estes ruídos, parecendo não ter consequências e gravidade imediatas, contudo, o sistema auditivo humano sofre um envelhecimento prematuro além do evelhecimento normal, o que pode conduzir a uma surdez precoce, ou a uma menor sensibilidade auditiva em determinadas bandas de frequência.

De um modo geral, os ruídos podem ser classificados em 3 tipos: 
Ruídos contínuos - são aqueles cuja variação de nível de intensidade sonora é muito pequena em função do tempo.

Ruídos flutuantes - são aqueles que apresentam grandes variações de nível em função do tempo. São os ruídos mais comuns a que estamos expostos diariamente.

Ruídos impulsivos, ou de impacto - apresentam altos níveis de intensidade sonora, num intervalo de tempo muito pequeno. São os ruídos provenientes de explosões e impactos.

\section{Exposição ao Ruído da População Europeia e Portuguesa}

O Ruído constitui, actualmente, um dos principais problemas ambientais nas principais cidades europeias, contribuindo para a diminuição do bem-estar de grande parte da população e afectando o Homem nos planos somático, psicolígico e social.

Os ruídos urbanos estão cada vez mais presentes no quotidiano, invadindo residências, locais de trabalho, de lazer, hospitais e escolas, podendo prejudicar as relações sociais, a comunicação, o comportamento, o rendimento escolar e a saúde.

\footnotetext{
A preocupação com o ruído já existia nos tempos mais remotos. Uma das primeiras referências escritas sob o ruído foi feita por Phínio o Velho cerca de 600 a.C. deixando na sua obra Naturalis referência ao ensurdecimento de pessoas que viviam perto das cataratas do Nilo, relacionando desta forma a exposição ao ruído à surdez.
}

A OMS e a Comissão Europeia (CE), desenvolveram um estudo na região parisiense sobre as percepções do ambiente e os seus efeitos sobre a saúde na população. $O$ estudo mostrou que quase $75 \%$ da população parisiense se declara afectada pelo ruído no seu domicílio, e $25 \%$ está submetida frequentemente ou permanentemente ao ruído. O ruído figura, assim, entre os danos mais sentidos pelos parisienses na sua vida diária. No entanto, o ruído é, sobretudo, percebido pelos parisienses como um problema local de qualidade de vida, antes de ser objecto de preocupações sanitárias. Ainda que dois terços dos parisienses percebam o risco sanitário ligado ao ruído como elevado, as preocupações sanitárias declaradas para outros danos, como o amianto ou a poluição do ar, são claramente mais importantes.

No entanto, os efeitos do ruído ambiental sobre a saúde são numerosos. A OMS e a CE avaliaram a escala europeia, para cada um dos impactos sanitários atribuidos ao ruído (perturbações do sono, doenças cardiovasculares, perturbações da aprendizagem, zumbidos e incómodos), a carga de doença através do indicador quantitativo "anos de vida em boa saúde perdidos". Assim, foi estimado que pelo menos um milhão de "anos de vida em boa saúde são perdidos" cada ano na Europa ocidental sob o efeito do ruído causado pelas infraestruturas dos transportes (WHO, 2011).

Como refere este organismo (WHO, 2000), o ruído constitui um risco para a saúde pública, principalmente em situações de exposição a níveis de ruído elevados.

As principais fontes de ruído no interior dos locais são os sistemas de ventilação, as máquinas de escritório, os electrodomésticos, rádio, televisão, alta voz dos vizinhos. Existem outras fontes de ruído no exterior, como, por exemplo, as actividades de cafés e restaurantes, os desportos, os campos de jogos, as máquinas de cortar relva, as máquinas e os trabalhos da construção civil, por último, mas a mais importante, são os ruídos relacionados com as actividades de transporte (Fotografia 1).

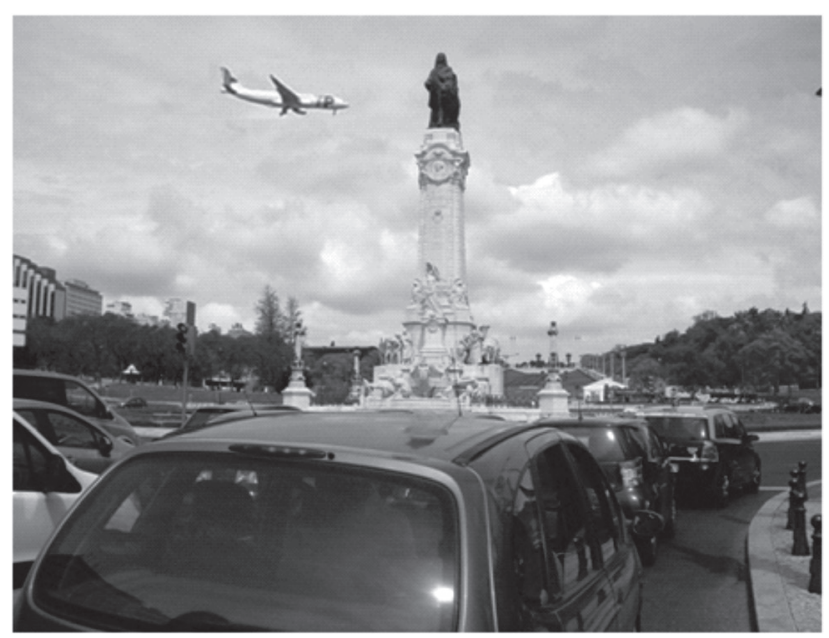

Fotografia 1: Principais fontes de ruído em Lisboa 
O ruído dos transportes representa igualmente um custo para a colectividade, na medida em que causa prejuízos na saúde física e psíquica e prejuízos económicos, geralmente suportados por quem não produziu esses ruídos. Distinguimos, assim, vários tipos de ruído.

1 - O nível de potência acústica de um veículo varia de forma complexa em função dos parâmetros de construção, do estado de conservação, da manutenção e dos parâmetros de utilização (regime motor, plena carga/carga parcial , velocidade e aceleração). Especial atenção deve ser dada aos veículos não conformes com o regulamento e os motociclos alterados.

Num veículo destacamos os seguintes ruídos:

- O ruído do motor e o ruído produzido por todos os sistemas auxiliares, e mecanismos de transmissão de potência; o ruído devido ao pavimento e à técnica de condução; o ruído de contacto pneu/ pavimento; o ruído de interacção entre o pneu o e veículo; o ruído aerodinâmico;

2 - O ruído do tráfego aéreo cujas características dependem do tipo de aeronave;

3 - O ruído dos comboios, constituídos pelos ruídos de rolamento, preponderante até às altas velocidades e os ruídos de origem aerodinâmica;

4 - Os ruídos ligados a actividades festivas e desportivas, os quais podem gerar níveis sonoros que incomodam bastante os residentes;

5 - Os ruídos de origem industrial os quais têm frequentemente a sua origem na utilização de numerosas máquinas e equipamentos, induzem ruídos complexos e embora temporários, são muito incomodativos;

Como se pode verificar no Quadro 2, na União Europeia, cerca de $21 \%$ da população habitando em meio urbano está sujeita a níveis de ruído superiores a Leq $=65 \mathrm{~dB}(\mathrm{~A})$ resultantes principalmente, do tráfego rodoviário. Este valor é considerado em muitos países como inaceitável.

\begin{tabular}{ll}
\hline $\begin{array}{l}\text { Nível de exposição diurno } \\
d B(A)\end{array}$ & $\%$ da população exposta \\
\hline$<55$ & 28,9 \\
$55-60$ & 26,9 \\
$60-65$ & 21,9 \\
$65-70$ & 14,7 \\
$70-75$ & 6,2 \\
Total & 100 \\
\hline
\end{tabular}

Quadro 2. Exposição da população da União Europeia ao ruído dos transportes

(Fonte: Lambert, 2000)

Segundo Lambert (2000), cerca de 80 milhões de pessoas na União Europeia estão expostas durante o dia a níveis sonoros que excedem $65 \mathrm{~dB}(\mathrm{~A})$. Durante a noite mais de 100 milhões de Europeus estão expostos a níveis que excedem 55 dB (A). Nestas situações inaceitáveis, o risco de perturbação do sono é muito importante (Figura 4).

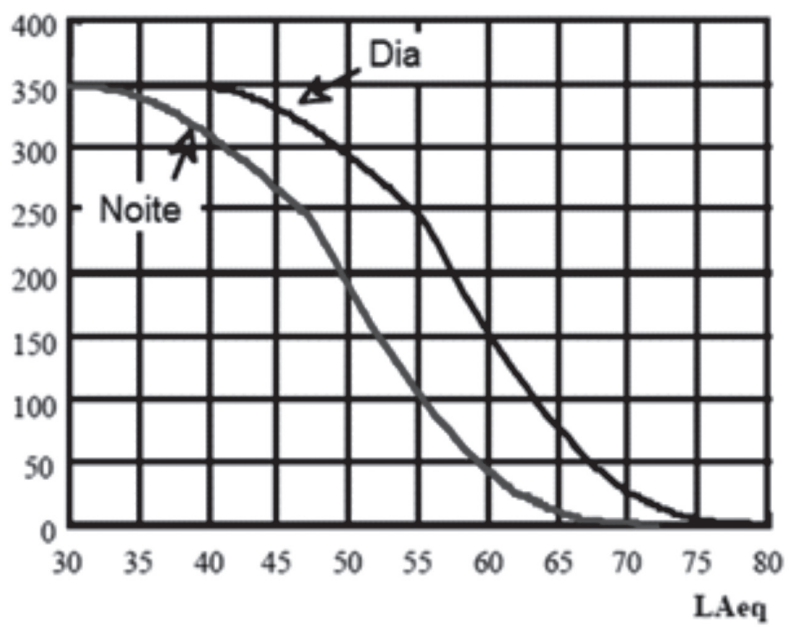

Figura 4. Exposição da população da União Europeia ao ruído dos transportes (população acumulada em milhões). (Fonte: Lambert, 2000) 
Verifica-se no Quadro 3, que para metade da população portuguesa o ruído emitido pelo tráfego automóvel é incomodativo. Contudo, o ruído que mais incomoda $70 \%$ da população portuguesa é o ruído emitido pelos motociclos.

\begin{tabular}{|c|c|}
\hline Fontes de ruído mencionadas & \% da população \\
\hline Motociclos & 69,5 \\
\hline Tráfego automóvel & 49,2 \\
\hline Buzinas de automóveis & 12,8 \\
\hline TV/rádios/gravadores/música alta & 12,5 \\
\hline Fábricas em funcionamento & 10,5 \\
\hline Pessoas a falarem alto & 9,7 \\
\hline Aviões & 9,6 \\
\hline Obras & 8,8 \\
\hline Sirenes & 6,2 \\
\hline Ruídos de vizinhança & 6,2 \\
\hline Comboios & 4,7 \\
\hline Bares/Discotecas & 3,5 \\
\hline Oficinas & 3,3 \\
\hline Festas/Feiras & 2,8 \\
\hline Alarmes & 2,3 \\
\hline Outras & 2,2 \\
\hline
\end{tabular}

Quadro 3. Ruídos considerados pela população portuguesa como mais incomodativos.

\section{Enquadramento Legal da Poluição Sonora}

Em Portugal, o Decreto-Lei n..$^{\circ / 2007}$, de 17 de Janeiro, aprovou o Regulamento Geral do Ruído (RGR) e revogou o Regime Legal da Poluição Sonora (RPLS), aprovado pelo Decreto-Lei n. ${ }^{\circ} 292 / 2000$, de 14 de Novembro, com as alterações introduzidas pelo Decreto -Lei n. ${ }^{\circ}$ 259/2002, de 23 de Novembro. O RGR estabelece o regime legal aplicável à prevenção e controlo da poluição sonora, harmonizando o regime com o Decreto -Lei n. $146 / 2006$, de 31 de Julho, que transpõe para a ordem jurídica interna a Directiva n. ${ }^{\circ}$ 2002/49/CE, relativa à avaliação e gestão do ruído ambiente. O Decreto-Lei n. ${ }^{\circ}$ 9/2007, de 17 de Janeiro, entrou em vigor parcialmente a 1 de Fevereiro de 2007, tendo sido posteriormente rectificado pela Declaracão de Rectificacão n. ${ }^{\circ}$ 18/2007, de 16 de Marco de 2007 e alterado pelo Decreto-Lei n. ${ }^{\circ}$ 278/2007, de 1 de Agosto.

No Regulamento Geral de Ruído destacam-se três períodos de referência: Período diurno - das 7 às 20 horas; Período do entardecer - das 20 às 23 horas; Período nocturno - das 23 às 7 horas.

O RGR aplica-se às actividades ruidosas permanentes e temporárias e a outras fontes de ruído susceptíveis de causar incomodidade, designadamente:

a) Construção, reconstrução, ampliação, alteração ou conservação de edificações;

b) Obras de construção civil;

c) Laboração de estabelecimentos industriais, comerciais e de serviços;

d) Equipamentos para utilização no exterior;

e) Infraestruturas de transporte, veículos e tráfegos;

f) Espectáculos, diversões, manifestações desportivas, feiras e mercados;

g) Sistemas sonoros de alarme.

O RGR é igualmente, aplicável ao ruído de vizinhança, contudo, não se aplica à sinalização sonora de segurança das passagens de nível. 
As câmaras municipais devem elaborar mapas de ruído para apoiar a elaboração, alteração e revisão dos planos directores municipais e dos planos de urbanização. Por seu lado, as autoridades policiais podem suspender actividades ruidosas temporárias e obras no interior de edifícios durante o periodo nocturno. Se o ruído se verificar no periodo diurno ou entardecer, as autoridades policiais podem fixar, ao produtor de ruído de vizinhança, um prazo para cessar a incomodidade.

Nas definições destacam-se novos indicadores de ruído:

Indicador de ruído diurno-entardecer-nocturno $\left(\mathrm{L}_{\text {den }}\right)$ : o indicador de ruído, expresso em $\mathrm{dB}(\mathrm{A})$, associado ao incómodo global, dado pela expressão:

$L_{d e n}=10 \times \log \frac{1}{24}\left[13 \times 10^{\frac{L_{d}}{10}}+3 \times 10^{\frac{L e+5}{10}}+8 \times 10^{\frac{L_{n}+10}{10}}\right]$

Em que $L_{d}$ «Indicador de ruído diurno» é o nível sonoro médio de longa duração, determinado durante uma série de períodos diurnos representativos de um ano;

Em que $L_{e}$ «Indicador de ruído entardecer» é o nível sonoro médio de longa duração, determinado durante uma série de períodos do entardecer representativos de um ano;

Em que $L_{n}$ «lndicador de ruído nocturno» é o nível sonoro médio de longa duração, determinado durante uma série de períodos nocturnos representativos de um ano.

O RGR estabelece valores limites de exposição:

Em função da classificação de uma zona como mista ou sensível, o RGR estabelece no artigo $11^{\circ}$ os seguintes valores limites de exposição ao ruído ambiente exterior (Quadro 4).

\begin{tabular}{lll}
\hline Tipo de zona & $\begin{array}{l}\text { Descritor } \\
\text { Lden } \\
(\mathrm{dB}(\mathrm{A}))\end{array}$ & $\begin{array}{l}\text { Descritor Ln } \\
(\mathrm{dB}(\mathrm{A}))\end{array}$ \\
\hline Zona Mista & a) & a) \\
Zona Sensível & a) & a) \\
Zona Sensível com uma & \\
grande infra-estrutura de & \\
transporte em exploração na & \\
proximidade & \\
$\begin{array}{l}\text { Zona Sensível com uma } \\
\text { grande infra-estrutura de }\end{array}$ \\
transporte aéreo projectada \\
para a proximidade \\
$\begin{array}{l}\text { Zona Sensível com uma } \\
\text { grande infra-estrutura de } \\
\text { transporte que não aéreo } \\
\text { projectada para a proximi- } \\
\text { dade }\end{array}$
\end{tabular}

a) Os municípios podem estabelecer em espaços delimitados, designadamente em centro histórico, valores inferiores em $5 \mathrm{~dB}(\mathrm{~A})$ b) Valores limites a aplicar aos receptores sensíveis

Quadro 4. Valores limites de exposição ao ruído ambiente exterior (Fonte: RGR, 2007)

Quanto aos veículos rodoviários a motor, é proibido, nos termos do disposto no Código da Estrada e respectivo Regulamento, a circulação de veículos com motor cujo valor do nível sonoro do ruído global de funcionamento exceda os valores fixados no livrete, considerado o limite de tolerância de $5 \mathrm{~dB}(\mathrm{~A})$.

A Figura 5 indica a evolução do nível de ruído exterior na legislação europeia para veículos ligeiros e pesados. 


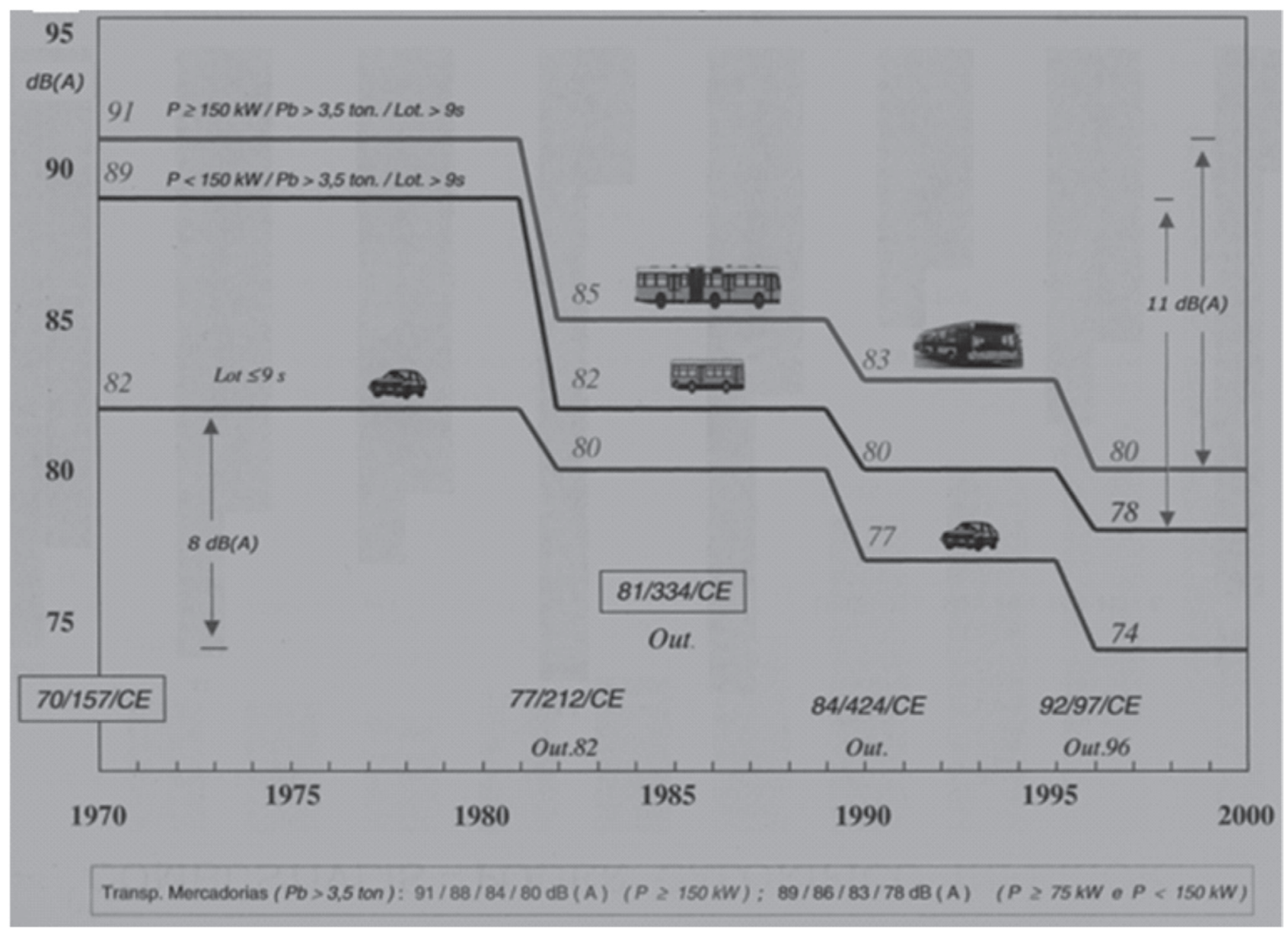

Figura 5 - Evolução dos limites do nível de ruído exterior (Nabais, 2005)

No caso de veículos de duas ou três rodas cujo livrete não mencione o valor do nível sonoro, a medição do nível sonoro do ruído de funcionamento é feita em conformidade com a NP 2067, com o veículo em regime de rotação máxima, devendo respeitar os limites constantes no presente Regulamento.

\section{Redução do ruído do tráfego em meio urbano}

Um veículo é composto de um grande número de peças. Quase todas são susceptíveis de produzir um som/ruído; todas estão em contacto e transmitem vibrações. Estamos perante uma cadeia de ruído extremamente complexa.

A luta contra a principal fonte de ruído em meio urbano pode ser conseguida através da implementação de várias medidas entre as quais: agindo sobre as fontes de ruído e deste modo reduzir o ruído na origem; agindo sobre a propagação do ruído, interpondo entre as fontes e os receptores sistemas de protecção passiva; restrições do tráfego urbano, privilegiando os transportes públicos; conectar os transportes em comum com as grandes infra-estruturas de transportes rodoviários, ferroviários, aéreos, etc; painéis que absorvem o ruído nas zonas com densidade de tráfego mais elevada; sanções efectivamente dissuasivas para os veículos que ultrapassam os limites de emissões sonoras; controlos do ruído mais adaptados às condições "normais" de utilização dos veículos; intervenções eficazes para descongestionar o tráfego, dando uma atenção particular à difusão dos corredores preferenciais e às vias reservadas ao transporte público; melhorar a qualidade do pavimento; reservar os estacionamentos aos residentes; favorecer a deslocação dos peões e dos ciclistas em condições de segurança. 
O nível do ruído rodoviário depende do tipo e do número total de veículos, da sua velocidade, da percentagem de veículos pesados e de veículos em aceleração e, por último, do revestimento do pavimento. Na cidade, devido aos limites de velocidade e à densidade de tráfego, os ruídos do motor e de escape são preponderantes. Além destes ruídos inevitáveis, existem outros ruídos que poderiam ser evitados ou pelo menos minimizados. São os apitos, os ruídos dos travões, os camiões de recolha do lixo indiferenciado e do camião de recolha do ecoponto, as motos em fase de aceleração e desaceleração brusca. São fundamentalmente estes ruídos que fazem aumentar bastante a incomodidade do ruído urbano. Estes ruídos podem e devem ser minimizados, através de soluções técnicas e alteração dos comportamentos.

As medidas de planificação da circulação podem ter uma influência sensível sobre a diminuição do ruído em zona urbana. Visam essencialmente agir sobre o volume e a natureza do tráfego, bem como, sobre a velocidade e a fluidez. Assim por exemplo:

- diminuir o número de veículos para metade, reduz o nível sonoro de $3 \mathrm{~dB}$;

- diminuir o número de veículos para um terço, reduz o nível sonoro de $5 \mathrm{~dB}$;
- diminuir o número de veículos para um décimo, reduz o nível sonoro de $10 \mathrm{~dB}$.

Medidas regulamentares podem ser adoptadas que limitem ou proíbem a circulação de determinados veículos ruidosos e poluentes e favorecam a circulação de determinados veículos mais silenciosos e menos poluentes, como os veículos eléctricos.

Barros (2011) realizou um estudo que coordenámos, sobre o ruído ambiente, num bairro habitacional na área metropolitana de Lisboa. Os objectivos do estudo consistiam na caracterização do ruído ambiente urbano de um bairro habitacional, bem como o seu incómodo para a população. Sendo o ruído ambiente urbano uma combinação de fontes sonoras, a avaliação adoptada foi baseada numa análise contínua do ruído durante um período de 7 dias consecutivos, 168 horas de medição. Durante sete dias e de forma contínua, fez-se a aquisição de níveis de pressão sonora e com um sistema de Trigger fez-se a gravação audio durante 1 minuto, sempre que o nível de pressão sonora ultrapassava $65 \mathrm{~dB}$. Os resultados mostraram o ruído característico de um bairro habitacional e misto da cidade de Lisboa, bem como permitiram identificar quais as suas principais fontes (Figura 6).

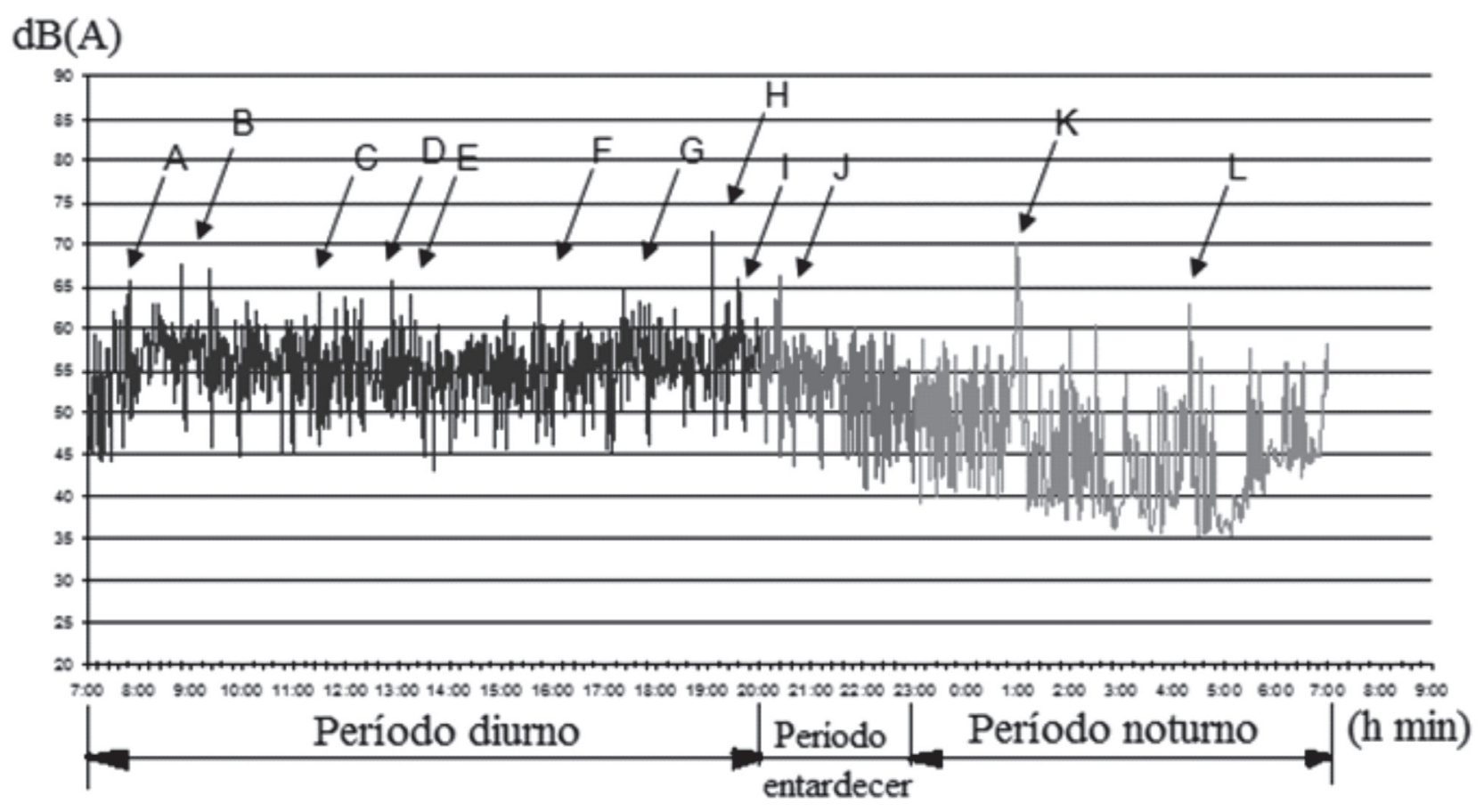

Figura 6 - Histórico temporal do dia 24 de Maio 2011 - 3a feira (Barros, 2011) 
Através da análise do histórico temporal dos níveis de pressão sonora e da gravação audio foi possível identificar para o dia 24 de Maio os seguintes acontecimentos: $A$. Evento não identificável - "algo cai na estrada; $B$. Veículo pesado a subir rua; C.D.G.H. Carro a buzinar; E. Algo a ser colocado em veículo de caixa aberta; F.I.J. Moto; K.L.Camião de recolha de lixo indiferenciado.

O gráfico do histórico temporal dos níveis de pressão sonora para um dia da semana permitiu identificar as principais fontes de ruído urbano, nomeadamente os eventos acima de $65 \mathrm{~dB}(\mathrm{~A})$, nomeadamente carros a buzinar ao longo do dia (eventos assinalados com $C, D, G, H$ ), sendo o evento assinalado com $\mathrm{H}$ correspondente a um carro a buzinar às 19 h 06 constituído o evento com nível mais elevado de ruído durante o período diurno com um nível de $71,1 \mathrm{~dB}(\mathrm{~A})$.

Durante o período noturno, os dois eventos que se destacam correspondem à passagem dos camiões de recolha do lixo. $O$ primeiro evento assinalado com $\mathrm{K}$ verificou-se às $0 \mathrm{~h} 58 \mathrm{~min}$ e registou um nível de $70,1 \mathrm{~dB}(\mathrm{~A})$. $O$ segundo evento embora com um nível inferior, não deixa de ser bastante incomodativo, dada a hora tardia a que se registou. Verificou-se às $4 \mathrm{~h} 19$ min e teve um nível de 63 $\mathrm{dB}(\mathrm{A})$. Apesar de haver razões para que a recolha do lixo se realize durante a noite, poder-se-ia tentar minimizar o ruído emitido pelos carros de recolha do lixo.

\section{Considerações Finais}

A poluição acústica e a poluição ambiental constituem na sociedade contemporânea dois dos principais problemas ambientais nas principais cidades do mundo, nomeadamente europeias, contribuindo para a degradação da qualidade de vida e da saúde de grande parte da população. Estas problemáticas exigem, igualmente, uma abordagem multi/interdisciplinar e multisectorial.

A invenção do automóvel accionado pelo motor de combustão interna, representou uma solução para a mobilidade, tornou-se objecto de desejo e de estatuto social. Contudo, um século mais tarde, quando reflectimos sobre as questões ambientais, a sustentabilidade, a qualidade de vida, constatamos que o automóvel representa o maior problema para o meio ambiente, dado que consome os recursos não renováveis, produz ruído e liberta gases com efeito de estufa e emite partículas de dimensões extremamente pequenas, mas potencialmente perigosas.

As tecnologias modernas ajudaram-nos a resolver muitos problemas, mas deram-nos também, o poder de perturbar e talvez de destruir o equilíbrio ambiental do nosso planeta.

Torna-se urgente reinventar o transporte ecológico, silencioso, inteligente e económico na aquisição, utilização, manutenção e em fim de vida, na sua reciclagem.

Para reduzir os ruídos, existem soluções de ordem legislativa e técnica. A aplicação das soluções de ordem legislativa e técnica relativa ao ruído são fundamentais. A luta contra o ruído deverá inscrever-se numa lógica de desenvolvimento sustentável. Só a tomada de consciência individual e colectiva sobre as consequências do ruído sobre o Homem, e o conhecimento dos mecanismos inerentes à origem, propagação e atenuação do ruído, poderá minimizar os seus efeitos nefastos e contribuir para a prevenção e resolução deste grave problema ambiental e de saúde pública.

A luta contra o ruído e a poluição deve ser feita em várias frentes simultaneamente: em nível dos transportes terrestres, aéreos, caminhos de ferro, das actividades industriais, da saúde pública, da educação ambiental, das liberdades individuais e das relações de vizinhança. Por outro lado, um reforço das sanções é necessário, mas não é suficiente.

São de maior relevância todas as propostas que vão no sentido da prevenção, da formação e da informação, sendo necessário unir esforços para uma cooperação eficaz entre todos os sectores e actores em causa.

Em relação ao ruído dos transportes são necessárias acções conjuntas dos construtores de automóveis, dos fabricantes de pneus, das empresas responsáveis pela construção das estradas e dos pavimentos e por fim, a mais importante contribuição vem, sem de dúvida, do condutor e da técnica da sua condução ecológica e silenciosa. 
Em meio urbano, a principal fonte de ruído, é constituída pelos transportes, essencialmente rodoviários, mas também os caminhos de ferro e os transportes aéreos. Poderá tentar-se diminuir o ruído, recorrendo a protecções acústicas clássicas que limitam a propagação das ondas sonoras. Contudo, uma concepção urbanística e arquitectural mais elaborada permite frequentemente obter a menor custo resultados mais satisfatórios. De igual modo, a aplicação das técnicas de isolamento acústico nas construções, nomeadamente, nas de habitação e serviços, permite melhor proteger os ocupantes dos danos de origem externa ou interna, reduzindo as perturbações de vizinhança.

A utilização massiva principalmente nos centros urbanos dos veículos eléctricos ajudará a resolver o problema do ruído de trafego automóvel e da poluição atmosférica.

O ruído e a poluição sempre foram percebidos como danos a combater, embora haja ainda muito a fazer, tanto em nível dos comportamentos, das atitudes, da legislação e da educação da população, como em nível da implementação de medidas de prevenção e do desenvolvimento da investigação nesta área.

\section{Bibliografia}

ACAP, estatísticas várias, http://www.acap.pt/autoinforma/ AGÊNCIA PORTUGUESA DO AMBIENTE. O ruído e a cidade http://www.apambiente.pt/politicasambiente/Ruido/SomRuidolncomodidade/Paginas/default.aspx

AGÊNCIA PORTUGUESA DO AMBIENTE. Projecto de Mobilidade Sustentável, Manual de Boas Práticas para uma Mobilidade Sustentável. Amadora, 2010.

ARAÚJO, M.I., SOARES, M. J. Educação Ambiental: o construto de práticas pedagógicas consolidadas na pesquisa de professores em escolas públicas. Ed. Criação, Aracaju, 2010.

AREND, M. Le bruit, phénomène social. In Bruit. Publication du Cercle Bruit Suisse, Lucerne, Septembre 1998.

BARROS, D. Análise e Caracterização do Ruído Ambiente Urbano - Cidade de Lisboa, Bairro Habitacional. Dissertação de Mestrado. Instituto Superior de Agronomia. Universidade Técnica de Lisboa, 2011.

COMISSÃO EUROPEIA. Comunicação da Comissão ao Parlamen- to Europeu, ao Conselho e ao Comité Económico e Social Europeu. Bruxelas, 2010.

DOMINGOS, O. Ruído Ambiente. Ambiente em Edifícios Urbanos. Coord. J. Patricio \& A. Santos. Laboratório Nacional de Engenharia Civil, Lisboa, 2000.

EEA . The European environment - State and outlook 2005. European Environment Agency, 2005.

EEA. Climate for a transport change - TERM 2007: indicators tracking transport and environment in the European Union. EEA Report No 1/2008, European Environment Agency, 2008a.

EEA. Energy and environment report 2008. EEA Report No 6/2008, European Environment Agency, 2008b.

EVANGELISTA, J. Razão e Porvir da Educação Ambiental. Instituto Nacional do Ambiente, Lisboa, 1992.

GOOD PRACTICE GUIDE FOR STRATEGIC. Noise Mapping and the Production of Associated Data on Noise Exposure, Version 2, 2007.

GUEDES, I. C. M. Influência da forma urbana em ambiente sonoro, Um estudo no bairro Jardins em Aracuju (SE).Univ Estatual de Campinas, Campinas, 2005.

HEIMANN, D.et al. (Eds.). Vivre à proximité des axes de transit Pollution atmosphérique, bruit et santé dans les Alpes. ALPNAP brochure. Università degli Studi di Trento, Dipartimento di Ingegneria Civile e Ambientale, Trento, I'Italie, 2007.

JOHNSON, D. What are we still doing wrong in assessing occupational noise exposure?, J. Acoust. Soc. Am., vol. 103(5), p. 2921, 1998. LAMBERT J. Le bruit des transports en Europe: exposition de la population, risques pour la santé et coût pour la collectivité. Colloque du Conseil National du Bruit, Paris, 12-13 Décembre 2000.

MARN. Plano Nacional da Política de Ambiente. Ministério da Agricultura e dos Recursos Naturais, Lisboa, 1995.

MARTINS, J. Motores de combustão interna. Publindústria, Edições Técnicas, Porto, 2011.

NABAIS, J. Sector dos Transportes:Uma perspectiva energética e ambiental. ETEPE, Edições Técnicas e Profissionais, 2ª Edição, Lisboa, 2005.

PATRÍCIO, J. Acústica nos edifícios. Verlag Dashöfer, Lisboa 2010. PORTUGAL. Constituição da República Portuguesa. VII Revisão Constitucional, 2005.

PORTUGAL. Gestão e Avaliação do Ruído Ambiente. Decreto-Lei n. ${ }^{146 / 06}$, de 31 de Julho.

PORTUGAL. Regulamento Geral do Ruído (RGR). Decreto-Lei n. ${ }^{\circ}$ 9/07, de 17 de Janeiro.

,SOROMENHO-MARQUES, V. O futuro frágil. Publicações Europa-América, Lisboa, 1998.

WHO (2000). Guidelines for Community Noise. 
WHO (2011). Impact sanitaire du bruit dans I'agglomération parisienne: qualification des années en vie en bonne santé perdues. OMS, ORS, BruitParif, Paris.

http://vancouver.ca/ctyclerk/cclerk/970513/citynoisereport/ index.htm\#membership

http://biblioteca.sinbad.ua.pt/teses/2009000599

Website: www.iambiente.pt

Website: www.europa.eu.int/comm/environment/noise/greenpap.htm

Website:http://eur-law.eu/PT/Parecer-Comite-Economico-Social-Europeu-sobre-tema-Emissoes,402884,d 